\title{
Ordnung muss sein: Vorwort
}

Dass wildes Brainstorming so viel ,Ordnung، nach sich ziehen würde, war während eines gemeinsamen Abendessens noch nicht abzusehen. Doch fügte sich eines zum andern: Projektskizze, CfP und diverse Anträge entwickelten sich zum „geregelten Zusammenhang“ einer Tagung im Frühjahr 2018 an der Universität Zürich. Und nun ist dank - durchaus komplexer - Ordnungsarbeit unter Beteiligung von vielen der vorliegende Band entstanden.

Die „Erzählten Ordnungen“ wären eine Idee geblieben, hätten wir nicht von verschiedener Seite wertvolle Unterstützung erfahren: Christian Kiening hat unser Vorhaben von Anfang an als wissenschaftlicher Austauschpartner begleitet; Sandra Bayers Illustrationen sowohl auf dem Tagungsdesign wie auch innerhalb dieses Bandes ermöglichten die graphische Gestaltwerdung unserer Ordnungsvorstellungen; alle am Thema Interessierten haben durch ihre Diskussionsbereitschaft während der Tagung, durch ihre Vorträge und nun auch in ihren Beiträgen zu einem inspirierten und weiterführenden Ordnungsdiskurs beigetragen; die Reihenherausgeber der TMP ermöglichten uns ein Forum für die Veröffentlichung.

Für die großzügige finanzielle Unterstützung danken wir an dieser Stelle besonders dem Schweizerischen Nationalfonds, dem Graduate Campus, der VAUZ sowie dem Alumni Verein der Universität Zürich und nicht zuletzt dem Lehrstuhl von Christian Kiening.

Zürich, im Juli 2020

Daniela Fuhrmann und Pia Selmayr 
